\title{
Del Eternauta al "Nestornauta": la transformación de un icono cultural en un símbolo político
}

\author{
Pablo FrancescutTi \\ Universidad Rey Juan Carlos
}

(Abstracts y palabras clave al final del artículo)

Enviado: 13 de agosto de 2015

Aceptado: 20 de agosto de 2015

\section{INTRODUCCIÓN}

A finales de agosto de 2010, las paredes de Buenos Aires amanecieron empapeladas con unos llamativos carteles. Mostraban el dibujo de un individuo embutido en un mono y con la cara protegida por un visor de submarinismo. Al observador avisado no le costaba trabajo reconocer la reproducción de la portada de El Eternauta, la historieta argentina más prestigiosa, aunque sin duda le desconcertaría la leyenda que convocaba a un mitin en apoyo a la presidenta Cristina Fernández, diciendo: "Néstor le habla a la juventud". Alertado por estas palabras, una mirada más atenta le permitía descubrir, bajo de la máscara de buceo, el rostro de Néstor Kichner (figura 1).

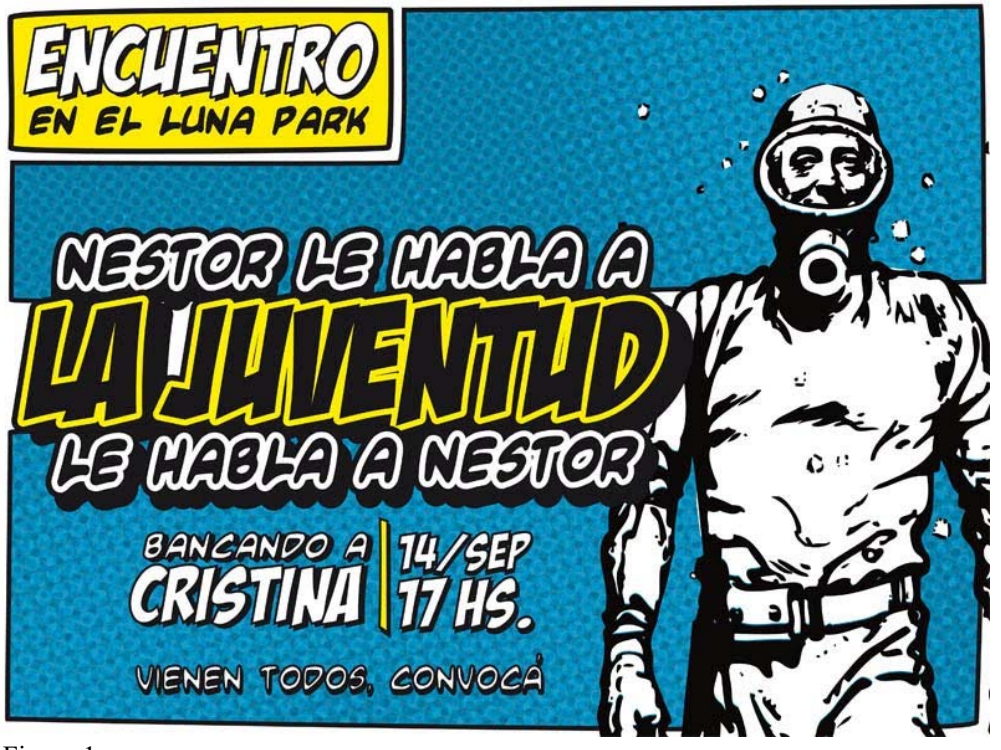

Figura 1. 
Enseguida comenzó a hablarse del "Nestornauta", y mucho más se habló cuando la súbita muerte de Kirchner, ocurrida poco más tarde, impulsó a sus seguidores a difundir esa imagen con profusión. Su objetivo era claro: enaltecer al expresidente aprovechando el prestigio del Eternauta, cumbre de la cultura de masas argentina y símbolo de la resistencia a las dictaduras.

No era la primera vez que un personaje de cómic servía de referente nacional. En su día, Superman fue considerado un emblema del poderío estadounidense. Hoy, Tintín se ha vuelto parte insustituible de la "Marca Bélgica", y Astérix se asocia a la legendaria prosapia gala. Pero en ninguna ocasión un mandatario había sido asimilado a un personaje de cómic con fines laudatorios.

La singularidad del caso mencionado justifica sobradamente su estudio. En este trabajo repasaremos la consagración del Eternauta en icono cultural y su ulterior metamorfosis en el "Nestornauta", con la intención de que su análisis arroje luz sobre la génesis y el proceso de consagración de los iconos, así como sobre su papel en la producción social del carisma.

\section{MARCO TEÓRICO Y METODOLÓGICO}

Durante largo tiempo, el término "icono" remitió a un tipo de imaginería religiosa circunscrita al cristianismo ortodoxo; de hecho, el vocablo procede de la iglesia bizantina, derivado del griego "eikon": imagen, similitud, retrato. En el mundo académico predomina en cambio la definición más acotada que acuñó Charles S. Peirce: signo que se refiere al objeto al que denota meramente en virtud de caracteres que le son propios, y que posee igualmente, exista o no exista el objeto (1974: 30). Fuera de los claustros, la palabra icono ha cobrado resonancia masiva de la mano de la jerga informática, en el sentido de "representación gráfica esquemática utilizada para identificar funciones o programas" (R.A.E.), o como designación periodística de tipos ideales representativos de determinadas cualidades, identidades, gustos, etc. (se habla así de Elvis Presley, icono de la subcultura juvenil, o de Madonna, icono gay). A rebufo de la obsesión por las celebridades desatada en los años noventa, la dupla ícono/icónico ha sustituido a la pareja "mito/mítico" que el habla común aplicaba a fenómenos similares. Esta acepción es la que aquí nos interesa estudiar.

Partimos de la premisa que los iconos, cuyo sustrato pueden ser personas reales, objetos, instituciones o personajes ficticios, encarnan, condensan o personifican el principio identitario de una comunidad o cultura histórica y geográficamente acotada; y conectan con las políticas modernas de reconocimiento, en tanto vehiculizan afirmaciones de autoridad o representatividad cultural. Un individuo icónico es ejemplar, de una ejemplaridad positivamente connotada y por lo general relacionada con la cultura.: "El significado de los individuos icónicos emerge en los rituales sociales de inscripción y reinscripción, valorización y contestación mediante los cuales los grupos contendientes buscan reescribir el contenido simbólico de los iconos culturales para hacerlos 'encajar' en las imágenes preferidas de sí mismos y servir a sus propósitos pragmáticos”, apunta Leypolt (2010: 9). 
Desde la sociología de la cultura, Jeffrey Alexander (2010) caracteriza al icono como una forma de representación colectiva que juega un rol capital en la construcción de significados en la sociedad actual. Símbolo material capaz de seducir públicos y obtener reconocimiento, adquiere su sentido en la interacción de su estructura estética superficial con la dicotomía sagrado/profano subyacente, trufada de elementos totémicos y esperanzas de salvación.

A diferencia de las ejemplaridades tradicionales, la iconicidad cultural no se concibe al margen de su expresión visual. El icono se manifiesta fenomenológicamente como una imagen o serie de imágenes nítidamente diferenciadas, durables y reproducibles, presentes en la memoria de grandes grupos sociales. Emparentado a las estrellas de cine, de cuyo glamour, fantasía y culto se ha impregnado, es característico de la civilización de la imagen, y su génesis y difusión se halla ligada a los soportes iconográficos de nuestro tiempo: cine, televisión, fotoperiodismo, cartelería...

Los iconos existen en estado dinámico: la cara de Nelson Mandela tras los barrotes de su celda pasó de simbolizar la lucha contra el apartheid a la concienciación sobre el sida (Tomaselli \& Shepperson 2009). Condensados semánticos visualmente plasmados, algunos se asocian a identidades nacionales como la Estatua de la Libertad; la cabina teléfonica roja y la torre Eiffel, iconos de la americanidad, la britanidad y la francesidad respectivamente. Tales identidades se apoyan en la continuidad histórica de su sustrato material y en narraciones dramáticas generadas y recibidas en comunidades receptivas al desarrollo de los significados icónicos (la Estatua de la Libertad, por ejemplo, es un monumental símbolo nacional que abarca significaciones que van de la amistad franco-americana (para los donantes franceses), a la lucha contra la esclavitud (para los afro-americanos) o a la promesa de un mundo mejor (para los inmigrantes) v. Nye 1994: 262ss).

Nuestro caso de estudio tiene que ver con esto último, toda vez que concierne a un icono (el Nestornauta) cargado de significaciones alusivas a ciertas maneras de entender la argentinidad contemporánea. Tiene además la particularidad de ser un símbolo derivado, surgido de la resemantización de otro preexistente (el Eternauta) a resultas de una acción de propaganda política.

A través del estudio de uno y de otro pondremos de relieve cómo se fraguan los iconos culturales, las mutaciones semánticas y visuales que experimentan a lo largo de su andadura y el papel que juegan en su consolidación sus valedores, y cómo cristalizan en palimpsestos compuestos por capas de significados sociopolíticos. Su naturaleza visual inspira al análisis la tarea de centrarse en sus imágenes más conspicuas y en su relación con los textos anexos. Los resultados obtenidos se cotejarán con los discursos sociales alusivos, con la intención de conocer el grado de acogida en su comunidad destinataria y su arraigo en la memoria colectiva.

\section{ANTECEDENTES}

El Eternauta es el nombre de una saga de historietas creada en Argentina por el guionista Héctor Germán Oesterheld y los dibujantes Solano López y Alberto Breccia. Su primera parte se publicó por entregas entre 1957 y 1959, en las postri- 
merías de la Edad de Oro del cómic local caracterizada por la ebullición editorial y un público compuesto por millones de niños y jóvenes adultos. Su éxito se debió en gran parte a la originalidad de su tema: una invasión extraterrestre a Buenos Aires, que ponía a los argentinos ante un horizonte de esclavitud o aniquilación. Su desenlace circular devolvía la trama al momento previo a la agresión, abriendo la posibilidad de una secuela.

En 1969, una nueva versión se dio a conocer en el semanario Gente. Para ese entonces el guionista había radicalizado su postura política y, en un giro inasumible para una revista conservadora que replicaba la mezcla de actualidad y periodismo de celebrities de Paris Match, hizo de la agresión alienígena la desembozada metáfora de la penetración imperialista en el Tercer Mundo. La sustitución del realismo de López por los trazos experimentales de Breccia coadyuvó al precipitado final de lo que pasó a llamarse El Eternauta de Oesterheld y Breccia. En 1976, la Editorial Récord publicó la Primera Parte en su formato original: cuadernillos semanales cuya portada enseñaba al Eternauta marchando con su fusil bajo la nevada mortal lanzada por los invasores. La formación de un público integrado por adultos nostálgicos y una joven generación de lectores movió al editor a encargar a Oesterheld y López la continuación de la saga. Entre 1976 y 1977 se publicó por entregas la Segunda Parte, concluida poco antes de que el guionista fuera secuestrado por los militares, debido a su militancia en la organización peronista Montoneros.

\section{EL PROCESO DE CANONIZACIÓN}

Los años siguientes fueron testigos de la paulatina canonización del Eternauta y del conjunto de las creaciones de Oesterheld. Sus impulsores celebraban su factura autóctona, sus postulados éticos (Trillo y Saccomanno 1980) y su "nacionalización de la aventura" (Sasturain 1995), esto es, su capacidad para aclimatar fórmulas extranjeras a la idiosincracia local. Que se califique de "nacionalización" a lo que no es sino una traducción intersemiótica1 delata la intención de homologarla a la política estatista del gobierno de Perón, haciendo de Oesterheld el partícipe de un proceso de sustitución de importaciones tendente a asegurar la soberanía argentina.

Otro aspecto ensalzado era el tópico del "héroe colectivo". En los guiones de Oesterheld, el exacerbado heroísmo individual cultivado por personajes como Superman, Batman y Capitán América era sustituido por las iniciativas de gente sencilla: vecinos de barrio, reclutas, ciudadanos de a pie... En la Primera Parte, el pro-

\footnotetext{
1 Por traducción intersemiótica se entiende la incorporación a una semiosfera de un elemento externo mediante la adecuación a sus códigos internos. Lejos de ser un fenómeno puntual, constituye la base misma del funcionamiento de las culturas, que existen en un proceso incesante de incorporación y exclusión de elementos ajenos (v. Lotman, 1996). En ese proceso se traducen piezas literarias, géneros artísticos, prendas de vestir, recetas de cocina, doctrinas, etc. Hay traducciones eficaces y traducciones mediocres; únicamente las primeras tienen un impacto duradero en la cultura receptora. En ese sentido, la recreación hecha por Oesterheld de las fórmulas del cómic extranjero sería equiparable a las traducciones de Borges de la novela policial inglesa o al uso por parte de Rodolfo Walsh del reportaje de investigación inventado por el periodismo estadounidense: todas son traducciones bien logradas.
} 
tagonismo recaía en el grupo de supervivientes integrado por la familia de Juan Salvo - dueño de un taller de transformadores - un profesor y un obrero metalúrgico, secundados por un jubilado, un periodista y militares de baja graduación. En el heterogéneo conjunto se ha querido ver una muestra a pequeña escala de la alianza de clases propugnada por el gobierno de Frondizi, bajo cuyo mandato se publicó la serie (Sasturaín 1995: 188), aunque la composición de tal grupo y los valores abrazados en esta y otras piezas de Oesterheld trascienden la coyuntura política, explicándose mejor a la luz del humanismo progresista que animaba al realismo social del cine y la literatura de los años treinta y cuarenta (la novela Las Uvas de la Ira de Steinbeck, por ejemplo) y de la ideología antifascista del guionista (Francescutti 1992²) .

De esa tesitura se aparta la Segunda Parte. Juan Salvo, el Eternauta, transformado en un mutante con dones sobrehumanos, organiza la insurrección de los supervivientes que, a un alto precio en vidas humanas, expulsa al invasor. En vez del traje aislante - versión improvisada del jumpsuit omnipresente en el vestuario de la ciencia ficción), Francescutti, 2013: 44-, ahora viste el uniforme de un comando especial, la indumentaria apropiada para un implacable profeta armado que decide por su cuenta cómo actuar y a quiénes inmolar en pos de la causa. La intriga, imbuida del vanguardismo voluntarista de la guerrilla latinoamericana, abandona toda noción de héroe colectivo en favor del culto al guerrillero heroico cristalizado tras la muerte del Ché (Francescutti 2007).

Cabe apuntar que la reivindicación de un género juzgado menor no era un fenómeno exclusivamente criollo. Su revalorización arrancó en Europa en los años '60, de mano de una visión de la cultura de masas a contrapelo de las jerarquías de la "alta cultura". Impulsada por semiólogos como Umberto Eco (1964) y por los mismos dibujantes (la etiqueta de "noveno arte" impuesta al cómic por Morris, el creador de Lucky Luke), la nueva mirada se plasmó en Argentina en una Bienal Internacional de Historieta auspiciada en 1968 por el vanguardista Instituto Di Tella, en donde por primera vez las viñetas fueron colgadas como pinturas. Detrás de la iniciativa se hallaba Oscar Massotta $(1967 ; 1970)$, autor del primer discurso crítico sobre ese medio, recogido en la revista Literatura Dibujada. Mas su enfoque semiótico apenas tuvo continuadores (Steimberg 1977, p. ej.); fueron intelectuales peronistas como Trillo, Saccomanno y Sasturain, quienes, al margen de posiciones académicas e interviniendo en el mercado editorial en calidad de periodistas y guionistas, promovieron una reflexión con objetivos bien diferentes: ya no se trataba de rescatar la historieta como arte ni de esclarecer su mecanismo de producción de sentido, sino de rehabilitar una forma cultural "nacional y popular" que tendría en Oesterheld su mejor exponente.

2 Es erróneo atribuir a Oesterheld la paternidad del heró́smo colectivo. Basta con remontarse a El Acorazado Potemkin (1924) de S. Eisenstein para encontrar una épica moderna a cargo de actantes sin nombre propio: los marineros y el pueblo de Odesa. El mérito del guionista argentino radica en su distanciamiento del elenco del cómic norteamericano, poblado de seres con poderes especiales (Superman y Batman) y héroes que imitan los patrones masculinos de Hollywood (Johnny Hazard, Rip Kirby, Steve Canyon...). 
El encumbramiento del Eternauta conllevó un movimiento simétricamente inverso: la devaluación de un vasto corpus que no se ajustaba a sus parámetros estético-ideológicos; en concreto, las historietas de Editorial Columba, cuyo predominio en el mercado disputaba la joven Editorial Récord para la cual trabajaban Trillo y Saccomanno como guionistas (Gago 2015). La pugna por la hegemonía del campo historietístico en nombre del legado de Oesterheld era un paso imprescindible en el camino a la legitimación de la obra y su guionista en estratos más amplios de la cultura argentina.

Las valoraciones de Trillo, Saccomanno y Sasturain no cayeron en saco roto, y la fama del Eternauta y su guionista no dejó de crecer. En un artículo publicado a finales de la dictadura, otro intelectual peronista, J. P. Feinmann (1982), se apoyó en la coincidencia temporal de la reedición de 1976 con el advenimiento del régimen de Videla para ver en la nevada que caía sobre Buenos Aires una metáfora premonitoria del golpe militar ${ }^{3}$. A ello se sumó el conocimiento de la condición de desaparecido de Oesterheld, expuesta en un póster publicado en 1983, en la revista Feriado Nacional, en el cual una muchedumbre formada por sus personajes se manifiesta bajo una pancarta que pregunta: “¿Dónde está Oesterheld?”. Esta lectura marcó un punto de inflexión en la semántica del icono. A su valor como modelo alternativo a la colonización cultural por parte del cómic estadounidense se añadió el significado antidictatorial aportada por esta reinterpretación de la Primera Parte y el trágico sino de su guionista derivado de su compromiso político.

Con la democracia proliferan los talleres, reediciones, coloquios y debates académicos en torno al Eternauta, alimentados por la exégesis incesante de la revista Fierro dirigida por Sasturain. Por fin llega el turno de los homenajes institucionales: en 1991, se instala en una estación del subterráneo porteño un mural con una viñeta de El Eternauta dibujado por Breccia; y en 1997 el Consejo Deliberante de Buenos Aires le pone el nombre de Oesterheld a una plaza de la ciudad. En el año 2000, la Primera Parte entra en el canon: Ricardo Piglia y Osvaldo Tcherkaski la incluyen en los clásicos de la literatura argentina editados por Clarín. Un dato significativo por partida triple: a) porque supone el aval de uno de los escritores más prestigiados; b) porque corre por cuenta de un gran grupo mediático privado, que luego se convertirá en el principal adversario del gobierno Kirchner; y c) porque la asimilación del cómic a las bellas letras - ya ensayada por Masotta al calificar al lenguaje de las viñetas de "literatura dibujada"- expone un mecanismo de consagración que opera igualando una forma subalterna a otra dominante ignorando sus grandes diferencias.

Los honores no cesan. En 2002, la muestra Héroes Colectivos organizada en Buenos Aires por el Ministerio de Cultura rinde tributo a la vida y obra del guionista y en el póster del evento el ya célebre personaje aparece con su máscara, su traje aislante, fusil y sus facciones ocultas por un resplandor blanco: un recurso despersonalizador empleado con el ostensible propósito de significar el heroísmo colectivo. A esas alturas la resonancia del Eternauta había trascendido los círculos de enten-

${ }^{3}$ A decir verdad, esa clave interpretativa le fue sugerida a Feinmman por el propio guionista. En la versión de 1969, un personaje dice a propósito de la nevada lanzada por los invasores: "Sus nevadas mortales eran... la miseria, el atraso, nuestros propios pequeños egoísmos manejados desde afuera". 
didos, conquistándole un puesto destacado en el panteón cultural argentino. Paradójicamente, su entronización coincidía con la práctica desaparición de los cómics locales (Vázquez 2010). A finales de los años noventa, acorraladas por la crisis económica y la importación de material extranjero, cerraron las dos editoriales principales, Columba y Récord. Semejante contexto tiñó al icono con un dato impuso al icono un tinte más nostálgico si cabe, pues a la evocación de una Edad de Oro pasada se añadió la añoranza de una de las pocas industrias culturales del país con identidad propia.

En 2007, al cumplirse cincuenta años de El Eternauta y treinta del secuestro de su creador, el museo Ferrowhite hizo imprimir con esténcil al ya célebre personaje en las paredes de Ingeniero White, junto con inscripciones alusivas a los desaparecidos de esa localidad bonaerense. La iniciativa se repitió el 24 de marzo de 2010: la efigie fue reproducida por los activistas en las columnas de la catedral porteña, acompañada de consignas del movimiento de los derechos humanos. La lectura política de la Primera Parte como alegoría de la resistencia peronista contra la dictadura de la Libertadora ${ }^{4}$ confluía con el antiimperialismo de la versión de Oesterheld y Breccia y el mensaje antidictatorial de la Segunda Parte, con el resultado de que la saga pasó a ser leída en clave de épica argentina contra la dominación extranjera y sus esbirros criollos.

Bajo el gobierno kirchnerista se produjo una nueva declinación con énfasis en la militancia de Oesterheld en la izquierda peronista de los años setenta, en la que militaron Kirchner y su esposa Cristina. El homenaje a una corriente que fue salvajemente reprimida por Isabel Perón primero y por la dictadura de Videla después era una de las banderas enarboladas por el Ejecutivo, junto con los juicios por violaciones a los derechos humanos perpetradas bajo el régimen militar.

Mas rehabilitar a aquella izquierda tenía sus bemoles. No resultaba fácil desvincularla de una metodología que casi nadie en la Argentina democrática reivindica. Observa Huyssen (2004) que la denuncia de los crímenes de la dictadura tuvo por contrapartida el olvido de las muertes causadas por las organizaciones guerrilleras. Una política de la memoria semejante se trasluce en el discurso apologético sobre el Eternauta: quienes elevaban la Primera Parte a símbolo de la lucha antiimperialista y colonial - una interpretación a todas luces forzada - pasaban de puntillas a la alegoría explícita de violencia montonera en la Segunda Parte (Palacios 2012), una secuela demasiado marcada por la mística del combatiente.

Soslayado el Eternauta montonero, los homenajes oficiales prosiguieron. El 25 de mayo de 2006, Kirchner invitó a la viuda de Oesterheld al palco que presidía los festejos de la jornada patria, y allí le confesó su admiración por la obra de su marido. En 2009, el Congreso declara el 4 de septiembre Día de la Historieta Argentina, conmemorando así la fecha de publicación de El Eternauta en 1957. En 2010, el Ministerio de Educación compra miles de ejemplares de la Primera Parte para su distribución en las escuelas secundarias. La Subsecretaría para la Reforma

${ }^{4}$ La Revolución Libertadora es el nombre que se dio a sí mismo el golpe cívico-militar que derrocó a Perón en 1955. Esta dictadura gobernó Argentina hasta mayo de 1958, enfrentándose a un movimiento masivo de huelgas, protestas y sabotajes denominado "la Resistencia Peronista". 
Institucional y Fortalecimiento de la Democracia organiza el taller de debate "El héroe colectivo"; el Ministerio de Trabajo diseña el juego de mesa "El héroe colectivo", basado en "la toma de decisiones grupales para enfrentar a un invasor"; y la feria científica Teknópolis publicita el "Primer Encuentro Internacional de la Historieta" con la imagen del Eternauta, que ilustra asimismo el programa "Sumergite en la lectura"de la Comisión Nacional de Bibliotecas Populares. El despliegue de distinciones encajaba al dedillo en la política cultural del Ejecutivo, interesada en afirmar un canon cultural afín a la estética "nacional y popular" cara al kirchnerismo.

En esta cuasi-sacralización las andanzas del personaje de ficción se solapaban con el recorrido vital de su autor. En la cada vez más tupida semántica del Eternata ganaba preeminencia la historia del autor que dignificó una expresión popular menospreciada batiendo a la penetración yanky en su propio terreno, probando que el Sur también existe para la aventura y que las épicas contra los alienígenas son tan imaginables en Buenos Aires como en Londres, Nueva Jersey y California. La gesta del héroe cultural se superponía a la saga del viajero de la eternidad, el vecino de barrio obligado por la adversidad a juntarse con otros porteños de a pie para enfrentar a los enemigos de la nación, demostrando que la patriada no necesita héroes ni superhéroes sino un liderazgo colectivo; todo ello adobado con la biografía del intelectual que pasó de su antiperonismo inicial a ofrendar la vida en la lucha contra la tiranía gorila. Y de telón de fondo, la Edad de Oro de la historieta argentina subsumida en el pasado dorado de los gobiernos de Juan Perón.

En esas circunstancias se produce la fusión del Eternauta con Kirchner. A diferencia del personaje de ficción, que intelectuales subalternos promovieron desde abajo hasta obtener el reconocimiento de la academia y las instituciones políticas, la trayectoria del Nestornauta discurre en sentido inverso, pues lo inventa una facción del partido gobernante y desde allí se irradia a sus huestes primero y a la opinión pública después. Dicha formación, creada en 2006 desde el gobierno, toma su nombre en referencia a Héctor Cámpora, el presidente que en encarnó las esperanzas de gran parte de la izquierda setentista. Tanto la denominación "La Cámpora" como el "Nestornauta" cumplían un mismo cometido: forjar vínculos históricos y afectivos entre Kirchner y una generación influida por la Juventud Peronista y la "historieta nacional".

La Cámpora multiplicó sus afanes para popularizar el nuevo icono. Al mes del fallecimiento del exmandatario, sus militantes cubrieron con impresiones las paredes de Buenos Aires. El Nestornauta apareció además en locales partidarios, en camisetas acompañadas de la inscripción "Mi único héroe en este lío" (el verso de una canción de la celebérrima banda de rock Redonditos de Ricota) e incluso en la página web de la agencia de noticias estatal Télam.

La jugada desató una polémica. La más sonada la protagonizó el conservador alcalde de Buenos Aires, Mauricio Macri, que vio en el reparto de la historieta en las escuelas una maniobra adoctrinadora, aunque luego aclaró que no se refería al Eternauta sino al Néstornauta, en una confusión que favoreció el designio de $\mathrm{La}$ Cámpora de fusionar ambas iconos. En las semanas siguientes, quienes defendían al 
Nestornauta y quienes denunciaban una apropiación espuria expusieron sus argumentos ante la opinión pública y los términos de la controversia quedaron fijados.

\section{ANÁLISIS DEL NESTORNAUTA}

Comenzaremos con la primera versión del Nestornauta, la del cartel convocando al mitin en apoyo a Cristina Fernández. Toma su inspiración de la imagen más conocida del Eternauta (figura 2), la de las portadas de la Primera Parte popularizadas por la reedición de 1976, que dio pie a las operaciones de consagración y exégesis descritas. El dibujo enfatiza la centralidad del protagonista, que avanza hacia el lector con una expresión de férrea determinación, bajo la nevada de la cual su indumentaria le protege. Para resumir el significado visual de estos trazos bastarían unas pocas palabras: "El Eternauta en marcha". ¿En marcha hacia adónde? No cuesta adivinar que hacia el cumplimiento de su misión, sea ésta la de salvar a su familia, combatir a los extraterrestres, etcétera.

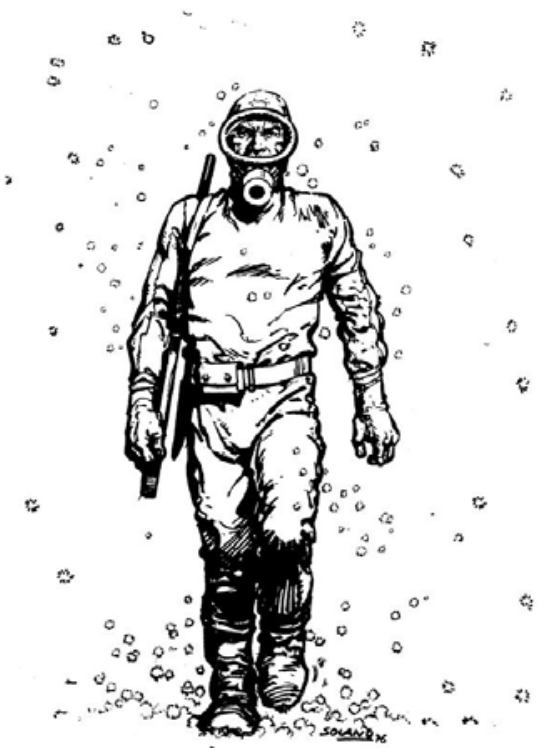

Figura 2.

El autor del Nestornauta recrea esa imagen manteniendo los copos que caen a su alrededor. Aparte de la superposición del rostro de Kirchner, otro detalle la diferencia del original: la ausencia del fusil que colgaba del hombro del Eternauta. Arma de caza menor, ésta tenía inicialmente la función de proteger a Juan y a los suyos de sus vecinos, a los que la catástrofe había arrojado a un estado de guerra de todos contra todos. Pero en el delicado trance de la recuperación de la memoria setentista, esa pieza, pese a ese uso defensivo, podía evocar el paroxismo militarista de la Segunda Parte; de ahí que los creadores del Nestornauta la suprimiesen con un toque de 
Photoshop que funciona en el plano icónico como un isomorfismo de la elisión discursiva del Eternauta montonero.

Otra discrepancia la pone la expresión risueña del Eternauta. El rostro ceñudo de Juan Salvo, enfrentado a la tarea casi imposible de proteger a su familia de un desastre sin cuento, es reemplazado por una faz alegre que recuerda la gran sonrisa de Perón, evocadora a su vez de la de Carlos Gardel, el gran icono argentino de la primera mitad del siglo XX. ¿Qué significa esto? Que el Nestornauta sonría en medio de los letales copos sugiere que se ríe de las armas de los invasores. Esta dimensión patémica no es baladí: a la disforia patente en el rostro del Eternauta y en el tono opresivo de una saga que en sus primeras versiones termina con el triunfo aplastante de los invasores, la destrucción de la Argentina y la huida por el tiempo de Juan ${ }^{5}$, se opone la euforia del líder que convoca a un acto político o a tareas edificantes en un marco de paz y democracia.

Pasemos a la leyenda que acompaña al dibujo: "Néstor le habla a LA JUVENTUD le habla a Néstor. Bancando ("apoyando", N. d. A.) a Cristina". Aludida en tercera persona, esa juventud es interpelada visualmente por el dibujo frontal del Nestornauta. Por medio de un guiño a uno de los iconos más afamados de la cultura de masas autóctona, esa franja de edad —el principal público consumidor de historietas - es convocada a reunirse con el ex presidente y a apoyar a su cónyuge.

Las siguientes versiones entraron en circulación tras el fallecimiento de Kirchner. Como se ha dicho, La Cámpora pintó al Nestornauta en los muros de Buenos Aires, emulando las intervenciones urbanas referidas al Eternauta. Esta vez no las acompañó de inscripción alguna, signo de que apelaban al registro visual de públicos más vastos que los militantes juveniles, públicos presumiblemente capaces de captar de un vistazo la alusión al personaje de historieta.

Un cartel de La Cámpora de febrero de 2011 muestra al Nestornauta asiendo un cubo de pintura y un rodillo (figura 3), junto a la leyenda "Florecen 1.000 flores, pintamos 1.000 escuelas" - eslogan de la campaña de pintada de escuelas lanzada por el gobierno nacional - y el añadido "Pinta tu escuela junto a La Cámpora". Aquí se muestra al Nestornauta cumpliendo tareas habituales del militante de a pie (pegar carteles, repartir propaganda, pintar consignas...). El anuncio tiene por enunciatarios a militantes y simpatizantes, y también a un público más vasto al que se le quiere informar de la implicación de esa corriente en la búsqueda del bien común. Por otra parte, la rima del eslogan con aquel otro de maoísta memoria, "que florezcan cien flores y que rivalicen cien escuelas", era otro guiño dirigido a los viejos miembros de la izquierda peronista, en cuyo ideario las citas de Perón se alternaban con las del Gran Timonel.

${ }^{5}$ El plexo de sentido movilizado por el icono Eternauta está teñido de nostalgia y melancolía. La exaltación del legado de Oesterheld y del heroísmo colectivo no logra conjurar la sombra de la victoria alienígena, de la crisis de la historieta nacional, del martirio de Oesterheld y los suyos. El triunfo simbólico que remata la Segunda Parte podría haber mitigado esa disforia, pero nadie quería ampararse en la sangrienta victoria militar obtenida por un guerrillero mesiánico. 


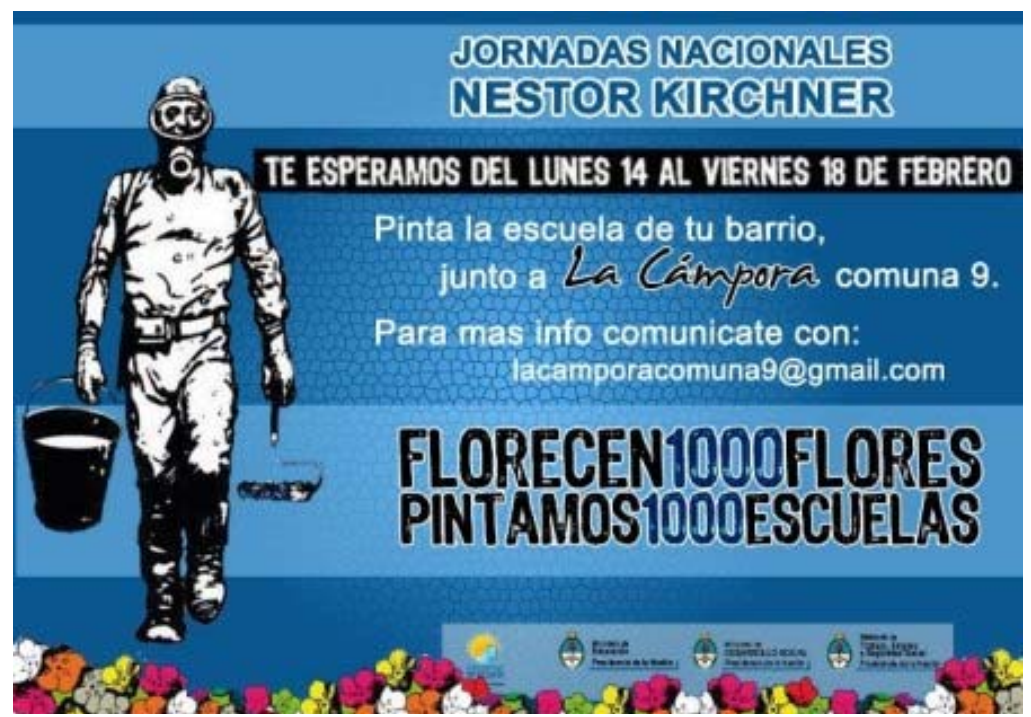

Figura 3.

Un dato a destacar: todas las versiones reproducen los copos del original, que componen una especie de aureola en torno del Nestornauta. Una aureola amenazadora, como advierte el paseante conocedor de la saga, familiarizado con su naturaleza radiactiva. La insistencia en este detalle no es banal; su presencia denota un interés por hacer visible la relación entre el personaje y la amenaza alienígena, y de esa manera acentuar su actitud heroica. Porque esta imagen también puede resumirse en unas pocas palabras: "El Nestornauta en marcha", ya que versa sobre un héroe que, pese a los peligros que le rodean, se abre paso en el cumplimiento de su misión (una misión que, que a tenor de los textos adjuntos, es de clarísima índole política).

Se aprecia en el instante que el Nestornauta aspira a absorber el espesor semántico movilizado por el Eternauta conectándolo, por vía del rostro de Kirchner, con el mandato presidencial que contribuyó a la definitiva consagración del autor y su personaje, y a la reparación simbólica de su asesinato con el juicio y castigo a los represores de la dictadura. De tal modo, personaje de historieta, guionista y líder peronista quedan fundidos en un nuevo icono de tono eufórico.

Entremos en la polémica. Gran parte de ella se centró en la legitimidad de la apropiación de un icono que parecía adscrito al patrimonio cultural general. En contra se manifestó precisamente uno de los gestores de la canonización del cómic, Guillermo Saccomanno, diciendo: "si algo encarnaba El Eternauta como serie era precisamente la destrucción del héroe en su concepción individual y romántica. Quienes hoy rondamos los sesenta años, casi la edad de Juan Salvo, sabemos de los riesgos de la construcción elitista del héroe como aventurero político" (2011).

En contra se posicionó el citado Macri en razón del uso propagandístico que se hacía del Nestornauta. En su denuncia el alcalde confundió el nuevo icono con su referente y anunció que vetaría su ingreso a las escuelas porteñas, teniendo después 
que aclarar que no se refería al Eternauta, cuya Primera Parte había distribuido en los colegios bajo su jurisdicción, sino al símbolo de La Cámpora: un lapsus revelador del rechazo del rechazo soterrado de los sectores conservadores a los significados de una obra cuya valía se ha vuelto "políticamente incorrecto" negar.

También se opuso Alejandro Scutti, director de la mencionada editorial Récord: "Están tergiversando el personaje, lo están politizando de alguna manera", denunció a La Nación. "Quieren poner a Kirchner como un héroe y mantenerlo en el tiempo. Como fue Perón en su momento (...) Somos los únicos titulares de los derechos de El Eternauta; molesta que nadie busque al titular pertinente de los derechos para hacer lo que hacen (...) El Eternauta ya está connotado como del Frente para la Victoria" (nombre de la alianza electoral controlada por el kirchnerismo, N. d. A.) .

La incongruencia del icono con su modelo era la esencia de la objeción interpuesta por Marco Novaro, autor de Historia de la Argentina 1955-2010. El sociólogo negó toda similitud entre el personaje ficticio, marcado por la continua exposición de su vida en situaciones límites, y el caudillo peronista, "un tipo que nunca corrió riesgos (...) que nunca se destacó por su audacia. Y por lo tanto nunca pagó costos personales. Acumuló recursos, hizo su fortuna personal, después acumuló recursos políticos, hizo una base de apoyo muy férrea y apostó a nivel nacional también sobre seguro (...) fue el prototipo del político que no corre riesgos; del Eternauta no tiene nada". En declaraciones al diario La Capital añadió: "El Néstornauta tiene un efecto de movilización dentro de las filas kirchneristas; es un artilugio, un recurso político partidario que alinea las filas, pero no recluta, no suma".

Más cruda fue la impugnación que recibió el flamante icono en las redes sociales. Al contrario del Eternauta, cuya consagración nunca fue contestada, el símbolo de La Cámpora enseguida fue objeto de sátiras en Twitter y Facebook. Una de la más difundidas recreaba el Eternauta con el fusil y una lluvia de billetes en lugar de copos de nieve; otra versión le ponía dos grandes bolsas de dinero en las manos (figura 4). El mote de "El Chorronauta" (traducible al castizo como "El chorizonauta") aludía a las sospechas de enriquecimiento ilícito que jalonaron la carrera de Kirchner. Así lo expresaban las leyendas: "Chorronauta: 1335\% 2003-2001. Crecimiento fortuna clan K"; o "Néstor Kirchner fue Presidente de la Argentina y fue el PEOR LADRÓN de la historia de nuestro país. No tiene nada que ver con la historieta del Eternauta". Con afán pedagógico, se exhortaba al lector a comparar el Eternauta y el Nestornauta, identificados respectivamente con los rótulos "Real "y "Falso".

A la protesta de quienes, en línea con Saccomanno, juzgaban incompatible el "héroe colectivo" y la exaltación del líder patente en el Néstornauta, Lautaro Ortiz, secretario de redacción de la revista Fierro, respondió en La Capital del siguiente modo: "Al tomar a El Eternauta, el kirchnerismo salió a proponer una lectura que, en realidad, no dista en nada de la que se propuso el mismo Oesterheld y de la que hicieron estudiosos de esa obra: la amistad, la lucha en conjunto, la misión colectiva, el destino de las sociedades, las propias fuerzas ante el enemigo". En similar tesitura se expresó Feinmann (2012) a propósito de las críticas de Macri: "El símbolo de la lucha por un país más justo, más libre, más democrático, que respete de una 
vez para siempre a todos los indios, a todos los morochos y a toda la buena gente. Ese es el mensaje. Eso significa el tan temido (...) Nestornauta. Nada mejor que ese mensaje de vida y de respeto por el otro".

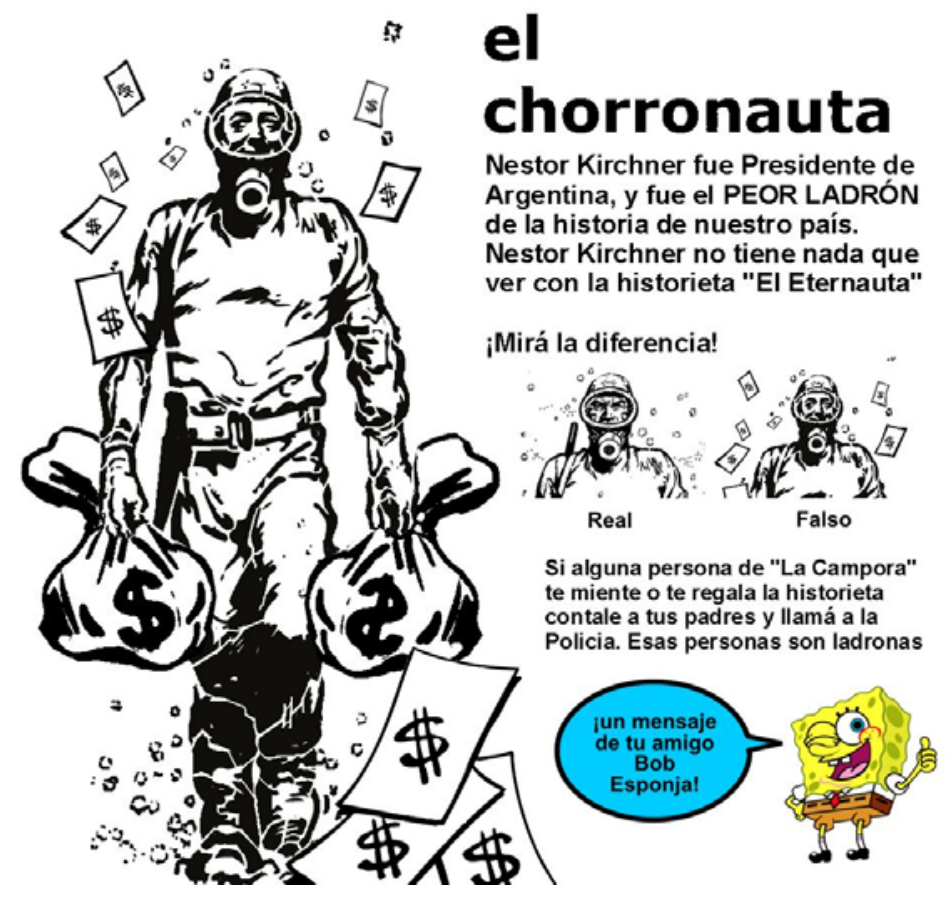

Figura 4.

Las alegaciones de los partidarios del Nestornauta giraban en torno a los méritos de Kirchner y su compromiso con los ideales defendidos en el Eternauta y por Oesterheld, esquivando la cuestión de su encaje con el héroe colectivo —o sea la disolución de la heroicidad en una pluralidad de actores- con la exaltación de un único actor dominante, el caudillo, una forma extrema del individualismo en política. No veían contradicción alguna en cantar las glorias del heroísmo colectivo en la historieta y glorificar el caudillismo en la historia real, ni en enseñar a los jóvenes a tomar decisiones grupales en el mundo de los juegos y exhortarles a encolumnarse tras el Jefe en el mundo de la política. Ningún valedor del Néstornauta se percató de que al alejarse del modelo actancial del primer Eternauta se aproximaba al héroe providencial del Eternauta montonero, en una coincidencia reveladora del culto al líder practicado por la izquierda setentista y el kirchnerismo.

La flagrante contradicción entre uno de los valores más exaltados del Eternauta y el individualismo del Nestornauta pone de manifiesto un cortocircuito ideológico similar al registrado en otros movimientos políticos que concedían al protagonismo de las masas una centralidad superior incluso a la que les daba el peronismo. Nos referimos al comunismo soviético y chino, y a su falta de reparos al conjugar una doctrina que hacía de la clase obrera el sujeto histórico de sus regímenes con la 
cuasi-divinización de Stalin, Mao y otros dirigentes, tributaria del culto a los héroes y a la personalidad mesiánica común en las sociedades capitalistas y precapitalistas ${ }^{6}$.

Si bien el Nestornauta no tiene nada de sorprendente en un movimiento personalista como el peronismo, la jugada se comprende mejor a la vista de la situación coyuntural de la facción kirchnerista. Kirchner llega a la Casa Rosada siendo el semidesconocido gobernador de una provincia poco importante. El vacío de poder abierto tras la gran crisis del año 2001 y la impugnación general a la clase política favorecen el ascenso de candidatos poco conocidos como él, que accede a la presidencia en 2003 con apenas el 22,2\% de los votos. Su debilidad le empujó a dotarse de una base social con medidas que apelaban a simpatizantes de la izquierda setentista y a una clase media ajena a la liturgia de Marchas Peronistas, banderas azul y blanca y efigies de Juan y Eva Perón. Le urgía disponer de una simbología propia, y aquí el Nestornauta resultaba doblemente ventajoso, pues promocionaba al nuevo jefe asociándolo a un icono popular mientras servía de logotipo a La Cámpora, una joven organización en busca de una identidad.

Para lo último hemos dejado un último aspecto importante: la novedosa equiparación de un dirigente justicialista a una figura de cómic. Lo indica José Natanson: "en los años setenta a nadie se le hubiera ocurrido transformar a Perón o Evita en un personaje de historieta" (2012). El peronismo siempre observó un respeto reverencial por la iconografía del líder y su mujer. El repertorio visual de la Juventud Peronista se basaba en fotografías oficiales a las que resignificaba añadiendo sus consignas. Que los partidarios de Kirchner recurran al registro del cómic en una construcción simbólica de carisma certifica la jerarquización de la historieta y del Eternauta en el sistema cultural, a la vez que da fe de las nuevas modulaciones del discurso político vernáculo, enriquecido con la retórica de la ironía y la complicidad del mensaje publicitario - muy dado a asociar toda suerte de iconos culturales a los productos que promociona - y el tono ligero de la euforia postmoderna.

\section{CONCLUSIÓN}

A lo largo del itinerario cumplido se ha visto cómo el icono cultural Eternauta se concretiza en imágenes nítidamente diferenciadas, perdurables y reproducibles, que perviven en la memoria de vastos colectivos sociales. Se ha visto además cómo en su gestación intervino una serie de actores que, a través de interpretaciones difundidas en los medios de comunicación, lo sacaron de los bajos fondos de la cultura hasta

\footnotetext{
${ }^{6}$ Bien mirada, la tensión entre el heroísmo grupal y el liderazgo individual ya asomaba en la portada de la Primera Parte: en ella no se veía ningún grupo; solo Juan Salvo enfundado en su traje aislante de fabricación casera y armado con su fusil bajo la nevada mortal. Pese al declarado protagonismo grupal, el "viajero de la Eternidad" sobresale en la trama por encima de los demás personajes, que acaban siendo eliminados, capturados o se extravían. Que las distintas versiones se llamaran "El Eternauta" y no "Los Eternautas" subraya la dificultad del guionista para romper con esquemas actanciales arraigados en las narraciones populares.
} 
obtener el reconocimiento de las instituciones hegemónicas, las cuales, a su turno, le insuflaron nuevos sentidos. El resultado es un amalgama narrativa sobre la identidad argentina, que abarca la autarquía del primer peronismo, los crímenes de la dictadura y las políticas de la memoria de la democracia. El alto nivel de consenso social subyacente a su iconocidad permite prever que el Eternauta mantendrá su encumbrado estatuto, aunque tal vez la faceta peronista realzada por el kirchnerismo pierda relevancia si éste sale de escena. Por lo pronto, su proyección no se ha debilitado; lo ejemplifica la instalación "Huellas de la invasión", que en la edición de 2014 de Tecnópolis recreó el imaginario de la Primera Parte.

Acto seguido, reconstruimos el lanzamiento del Nestornauta desde las alturas gubernamentales como una acción proselitista dirigida a promocionar, de manera desenfadada, al líder de una corriente peronista movilizando sentimientos identificadores entre su persona y una constelación de nociones, recuerdos y pasiones de la izquierda de los años ' 70 . Y hemos señalado cómo fue puesto de inmediato en entredicho a causa de su carácter abiertamente partidista y de las dudas a propósito de la legitimidad de su apropiación del Eternauta.

Una rápida búsqueda en Internet nos alerta de que la presencia pública del Nestornauta ha disminuido en los últimos dos años, circunscribiéndose al área de influencia de La Cámpora. ¿Cabe deducir que su dependencia del partido gobernante redujo su atractivo? A este respecto no se puede arriesgar una respuesta definitiva. No siempre el color político juega en contra del carisma icónico; lo prueba el calado de la figura del Ché Guevara en públicos refractarios a su exaltación de la violencia revolucionaria; sin embargo, conviene subrayar que en el cúmulo de significados que la atraviesa hay mucho más aparte de su ligazón con el castrismo (valores como el heroísmo individual, el desinterés y la juventud, y una biografía contada como una Pasión). El tiempo dirá si el Nestornauta trasciende las lindes del kirchnerismo o será recordado como un ingenioso recurso de mercadotecnia ${ }^{7}$. Y en tanto su suerte se dilucida, fungirá de síntoma de una sociedad que no termina de saldar cuentas con su pasado y sueña con ideales igualitarios mientras se rinde a los hombres providenciales.

\section{BIBLIOGRAFÍA}

AleXANDER, Jeffrey C. (2010), “The Celebrity Icon”, en Cultural Sociology, vol. 4 no. 3, pp. 323-336.

Di PAOlo, Marc (2011), War, Politics, and Superheroes: Ethics and Propaganda in Comics and Film, McFarland \& Company Inc., Jefferson.

\footnotetext{
${ }^{6}$ En la indisimulada vocación proselitista del Nestornauta radica su talón de Aquiles. El kirchnerismo podría haber optado por lanzar otro icono menos polémico. Un ejemplo en contrario lo ofrecen John Kennedy y Richard Nixon que, para rentabilizar la popularidad de la carrera espacial, prefirieron situarse en un muy distante segundo plano y promover a los astronautas al rango de iconos nacionales: la mejor manera de que su hazaña revirtiese en beneficio de sus administraciones (Nye, 1994: 239). Pero formular ese reproche a Kirchner supondría ignorar su modus operandi político, basado en la búsqueda de una incesante polarización de la opinión pública a favor o en contra de su gobierno.
} 
Eco, Umberto (1965), Apocalípticos e integrados, Barcelona, Lumen.

FERNANDES, Amaury (2014), "El Nestornauta: a HQ El Eternauta e o imaginário nacionalista na Argentina kirchnerista", en Z Cultural, año IX, $\mathrm{n}^{\circ} 3$ (consultado el 5 de junio en: http://revistazcultural.pacc.ufrj.br/el-nestornauta-a-hq-el-eternauta-e-o-imaginarionacionalista- $n_{j}$ argentina-kirchnerista/

Feinmann, José Pablo (2012), “Qué significa (hoy) el Eternauta?”, en Página 12, 27 de agosto. - (1982) "La nieve de la muerte cae sobre todos", en SuperHumor, no 21.

Francescutti, Pablo (2013), "La moda del futuro", en M. Serra y P. Francescutti (eds.) La exuberancia de los límites, Madrid, Biblioteca Nueva, pp. 39-56.

- (2007), "De vuelta al futuro con El Eternauta", en Punto de Vista n 8 87, pp. 13-18.

-(1992), “¿Quiénes son Ellos?”, en El Juguete Rabioso, nº 2, pp. 25-32.

GAGO, Sebastián H. (2015), "La lectura de Oesterheld antes y después del retorno democrático", en La Trama de la Comunicación, Vol. 19, pp. 131-149.

HuYSSEN, Andreas (2004), "Resistencia a la memoria: los usos y abusos del olvido público", conferencia presentada en el XXVII Congresso Brasileiro de Ciências da Comunicação, Porto Alegre.

LEYPOLDT, Gunter (2010), "Introduction: Cultural Icons, Charismatic Heroes, Representative Lives”, en Leypoldt y Bernd Engler (eds.) American Cultural Icons: The Production of Representative Lives. Königshausen und Neumann, Würzburg.

Lotman, Y. (1996), La semiósfera. Semiótica de la cultura y del texto, Madrid, Cátedra.

Massotta, Oscar (1967), "Reflexiones sobre la historieta" y "Evolución de la Historieta Americana", en Técnica de la historieta, Buenos Aires, Escuela Panamericana de Arte.

- (1970) La historieta en el mundo moderno. Paidós, Buenos Aires.

NatAnson, José (2012), "El lugar de La Cámpora”, en Página 12, 30 de septiembre.

Nye, David E. (1994), American Technological Sublime, The MIT Press, Cambridge, Mass.

PALACiOS, Cristian (2012), "Desfasajes. Entre la historieta y la política", en La Trama de la comunicación, vol.16, $\mathrm{n}^{\circ} 1$, consultado en: http://www.scielo.org.ar/pdf/trama/v16n1/v16n1a07.pdf

Peirce, Charles S. (1974), La ciencia de la semiótica, Nueva Visión, Buenos Aires.

ROJEK, Chris (2001), Celebrity, Reaktion Books, London.

Saccomanno, Guillermo (2011), "Adiós a Francisco Solano López, el dibujante de El Eternauta", en Página 12, 14 de agosto.

Sasturain, Juan (1995), El domicilio de la aventura, Colihue, Buenos Aires.

STEIMBERG, Oscar (1977), Leyendo historietas. Estilos y sentidos de un arte menor, Nueva Visión, Buenos Aires.

Tomaselli, Keyan G.; Shepperson, Arnold (2009), "The absent signifier:The morphing of Nelson Mandela", en K. Tomaselli \& D. Scott (eds.) Cultural icons, Left Coast Press, Walnut Creek, Cal., pp. 25-42.

Trillo, Carlos; Saccomanno, Guillermo (1980), Historia de la historieta argentina, Editorial Récord, Buenos Aires.

VÁzQUEZ, Laura (2010), "Los avatares del mercado de la historieta argentina: esplendor, crisis y renovación (1983-2001)", en R. Carbone y A. Ojeda Paradiso (eds.) De Alfonsín al Menemato (1983-2001). Literatura Argentina Siglo XX, Vol. 7, Buenos Aires, Fundación Crónica General. 


\title{
RESUMEN
}

La puesta en circulación en Argentina del "Nestornauta", un icono que combinaba rasgos del difunto presidente Néstor Kirchner y del Eternauta, el protagonista de la historieta más célebre del país sudamericano, brinda una oportunidad idónea para examinar cómo se fragua uno de esos símbolos, las mutaciones semánticas y visuales que experimenta a lo largo de su trayectoria y el papel que desempeñan las estrategias de sus valedores en su consagración. El análisis llevado a cabo pone de manifiesto cómo, a medida que los iconos van arraigando en una cultura, se transforman en palimpsestos compuestos por diversas capas de significados sociopolíticos.

Palabras clave: iconos culturales, historieta, Néstor Kirchner, Argentina.

\section{From The Eternaut to "The Nestornaut": the Transformation of a Cultural Icon into a Political Symbol}

\begin{abstract}
The diffusion in Argentina of the "Nestornauta", an icon with traits of the late argentinian president Nestor Kirchner and the Eternauta, the most celebrated comic character in this Southamerican country, gives us the opportunity to probe the process of icon making, the semantic and visual changes experienced by it throughout their history, and the role of its promoters in its enshrinement. The research makes it clear how these symbols, as become engrained in the culture, evolve into "veritable palimpsests of multilayered sociopolitical meanings".
\end{abstract}

Keywords: cultural icons, comic, Nestor Kirchner, Argentina.

\section{RÉSUMÉ}

La diffusion en Argentine de la "Nestornauta", une icône avec des traits de l'ancien président argentin Nestor Kirchner et l' Eternauta , le personnage comique le plus célèbre dans ce pays Southamerican , nous donne l'occasion de sonder le processus de l'icône, de décision, les changements sémantiques et visuelles vécues par elle tout au long de leur histoire, et le rôle de ses promoteurs dans sa consécration . La recherche montre clairement comment ces symboles, comme devenir enracinée dans la culture , évoluent en "véritables palimpsestes de significations sociopolitiques multicouches".

Mots-clé: icônes culturelles, comique, Nestor Kirchner, l’Argentine . 